\title{
Design and Manufacturing of Shuttlecock Throwing Robot
}

\author{
Somesh Budale*, Akshay Dhanrale, Akhilesh Joshi and Sanjay Matekar \\ Mechanical Department, Savitribai Phule Pune University, Pimpri Chinchwad College Of Engineering, Nigdi, Pune, Maharashtra, India
}

Received 05 May 2018, Accepted 08 July 2018, Available online 13 July 2018, Vol.8, No.4 (July/Aug 2018)

\begin{abstract}
Shuttlecocks are a common source of entertainment and sport, although the physics behind these shuttlecocks is often taken for granted. Shuttlecock operates under two main physical concepts, projectile motion and mass distribution. As shuttlecock throwing is a major sport in Vietnam, so we developed a robot for the same. This paper consists of Design, Manufacturing and Analysis of Shuttlecock Throwing Robot for various elevation, angle and range. It consists of design and fabrication of Chassis, Shuttlecock Throwing Mechanism, Shuttlecock passing mechanism and PCB circuit board. Also various results and data is concluded after testing the robot.
\end{abstract}

Keywords: Shuttlecock, PCB, Chassis, Projectile.

\section{Introduction}

Automation is one of the trending subjects surrounding the manufacturing industry in the 21st century and with good reason. Not only does it help manufacturers keep up with growing global demand, it also helps create new job opportunities as well as help a manufacturer progress into the 21 st century.

Shuttlecocks are a common source of entertainment and sport, although the physics behind these shuttlecocks is often taken for granted. Shuttlecock throwing is a major sport and even considered as a folk game in most part of Vietnam.

Vietnam is on the fast development track. However, the traditional culture is always treasured.

The game consists of an open field with a $15 \mathrm{~m}$ bamboo trunk planted in the middle. A bamboo ring is hung on top of the bamboo stick. The ring is covered in yellow and pink papers. Yellow color represents the moon, while pink represents the sun. The heart and soul of this game is the Shuttlecock. The shuttlecock is an object made of cotton balls or filled with rice husks, symbolizing prosperity and happiness. The shuttlecock is hung by a string sewn to the center of the Shuttlecock

It is decorated with colorful cotton representing the colors of the rainbow. When playing, the player holds the end of the string to swing it clockwise various times before throwing and aims for the center of the ring. If the shuttlecock makes it through the ring, the player wins. The flying shuttlecock depicts a flying dragon, iconic of human power and the universe. That's

*Corresponding author's ORCID ID: 0000-0002-8197-9470 DOI: https://doi.org/10.14741/ijcet/v.8.4.10 why the Shuttlecock Throwing Festival opening is commenced with a ceremony to pray for deitties of the Land and Sky.

After the first shuttlecock hits the target, it will be opened. The husks inside it are shared among the people as a wish for a prosperous year. Nobody knows when the game started. Today, it is not only a folk game for both men and women, where they can meet and find their other halves but also a sport for players to show their skills.

As shuttlecock throwing is a major sport in Vietnam, so we developed a robot for the same.Also, it is essential to understand the working and basic concepts of different components to be used for manufacturing of various mechanisms to be utilized in this robot.

\section{Scope}

The robot can be used in a variety of applications and in varied spheres influencing the human race. The various applications can be in the field of education, sports, defence as follows:

Stacking of goods in warehouse

Experimental setup is for educational purpose and that can be used in defence for launching purpose. Sports purpose

\section{Design}

Since the Shuttlecock flies using projectile concepts a basic review of projectile motion parameters and its working becomes essential. They are as follows: 


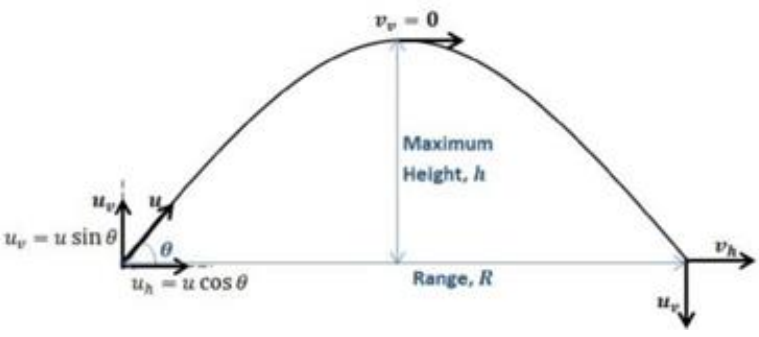

Figure1. Projectile motion

For a point mass the generalized projectile motion is as follows

$y=x \tan (\theta)-\frac{g * x^{2}}{2(\cos (\theta) * u)^{2}}$

$R=u^{2} * \sin (2 \theta) / g$

$H=u^{2} * \frac{(\sin \theta)^{2}}{2 * g}$

\section{Shuttlecock}

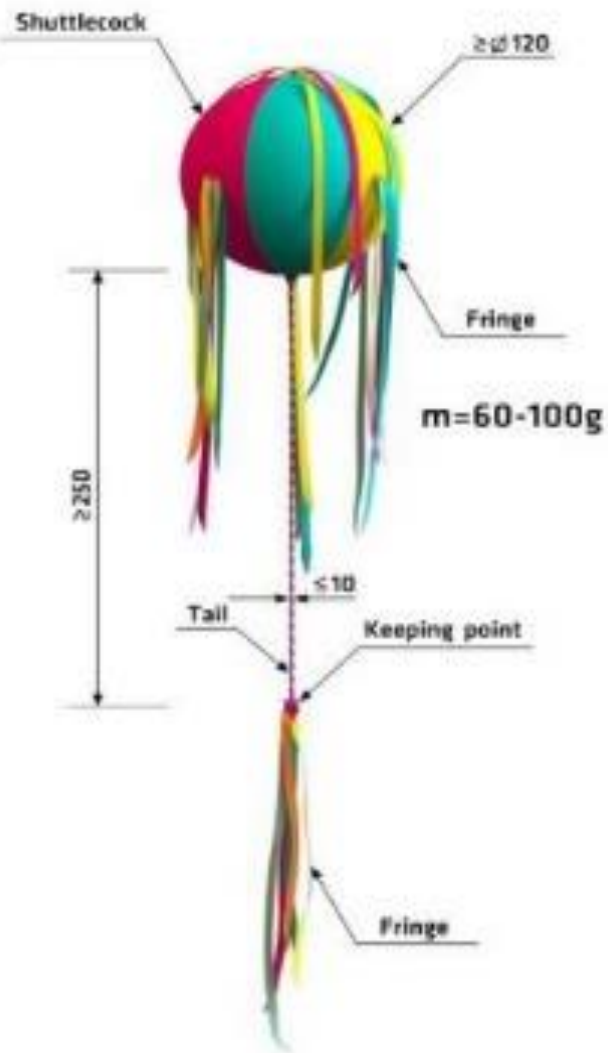

Figure.2 Shuttlecock

The conventional shuttlecock is quite different from the one that we have designed. It is spherical in shape having material natural fiber. It has additional fringes attached to it other than its spherical shape. During its projectile motion, drag and lift forces will act on it. The magnitude of lift forces will be very less as its shape is symmetrical.
The various forces acting on a shuttlecock are:

- Gravitational force

- Drag force

- Lift force

- Externally applied force

The mathematical modelling of the drag forces on the shuttlecock can be stated as follows:

Drag force:

$F_{D}=\rho * C_{D} * A * u^{2} / 2$

Drag force depends on

- Object size

- Object position

- Angle of projection

- Flow velocity and flow direction

\section{Chassis}

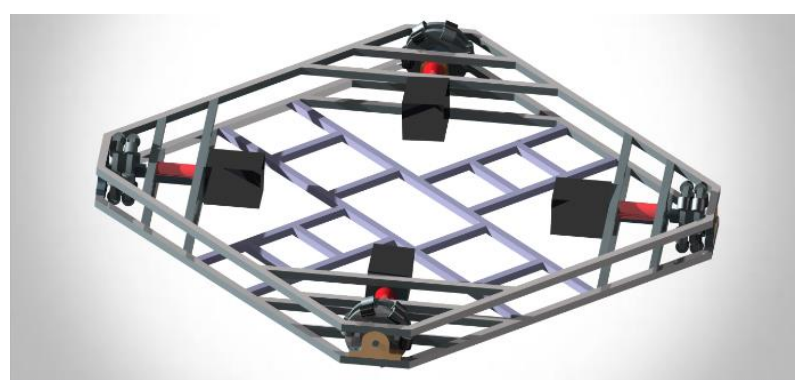

Photograph.1 Chassis

\begin{tabular}{|c|c|c|}
\hline S. No & Title & Specifications \\
\hline 1 & Type & Square double layered \\
\hline 2 & $\begin{array}{l}\text { Materials } \\
\text { used }\end{array}$ & $\begin{array}{l}\text { Aluminum square sections } \\
12 \mathrm{~mm} * 12 \mathrm{~mm}\end{array}$ \\
\hline 3 & Motor & $\begin{array}{c}\text { NEMA } 23 \text { Bipolar stepper motor } \\
\text { Speed- } 400 \mathrm{rpm} \\
\text { Torque- } 21 \mathrm{kgcm}\end{array}$ \\
\hline 4 & Wheels & $\begin{array}{c}\text { Omni-directional wheels } \\
\text { Diameter- } 100 \mathrm{~mm}\end{array}$ \\
\hline 5 & $\begin{array}{c}\text { Wheel } \\
\text { mountings }\end{array}$ & $\begin{array}{l}\text { Flange, rectangular hub, flexible } \\
\text { coupling, bearing }\end{array}$ \\
\hline 6 & Bearing & \\
\hline 7 & $\begin{array}{c}\text { Chassis } \\
\text { fabrication }\end{array}$ & Welding, Bolting, Riveting \\
\hline 8 & Power rating & $12 \mathrm{~V} \max 18 \mathrm{~A}$ \\
\hline
\end{tabular}

Fabrication of chassis

- The lower layer of chassis is manufactured by welding of the aluminium sections. First the sections were arranged according to the design, then the fixture was made. The welding was carried out starting from one of the corners.

- The flange, which is attached to the omnidirectional wheels, is made of aluminium and is manufactured by performing $\mathrm{CNC}$ and $\mathrm{VMC}$ operations. 
- $\quad$ The hub, which guides the flange is made of nylon and is manufactured by water jet operation and milling operation,

- The second layer of the aluminium is bolted and is placed near the wheel in order to avoid bending of the chassis.

- The bearing is press fitted into the hub and flange for smooth rotating operation.

- The supporting elements to the upper part of the robot which are made of aluminium sections are bolted to the chassis.

\section{Throwing Mechanism}

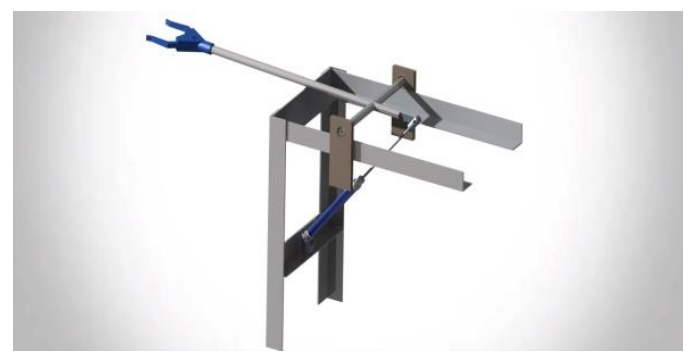

Photograph.2 Shuttlecock throwing mechanism

\begin{tabular}{|c|c|c|}
\hline S. No & Part & Specifications \\
\hline 1 & Pneumatic cylinder & $\begin{array}{c}\text { Double acting } \\
\text { Bore diameter- } 16 \mathrm{~mm} \\
\text { Stroke- } 150 \mathrm{~mm} \\
\text { Weight- } 500 \mathrm{~g} \\
\text { Make- JANATICS }\end{array}$ \\
\hline 2 & Throwing arm & $\begin{array}{c}\text { Material- Aluminium } \\
\text { Length- 850 mm }\end{array}$ \\
\hline 3 & Pneumatic gripper & $\begin{array}{c}\text { MHC2-16D (angular) } \\
\text { Make- SMC Pneumatics }\end{array}$ \\
\hline 4 & $\begin{array}{c}\text { Directional control } \\
\text { valve }\end{array}$ & $5 / 2$ solenoid operated spool \\
\hline 5 & Flow control valve & Manual setting screw type \\
\hline
\end{tabular}

This mechanism is used to throw the shuttlecocks through the rings. It consists of a throwing arm pivoted at specified distance. This arm has pneumatic gripper at one end and pneumatic piston at the other end. Pneumatic gripper is used to hold the shuttlecock and to release it instantly at the time of throwing the shuttlecock. Pneumatic piston provides necessary force to throw the shuttlecock through the ring.

\section{Pressure Regulator}

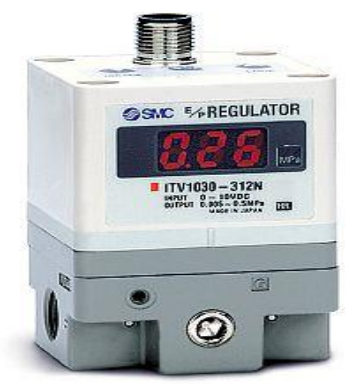

Photograph.3 Pressure regulator
Pressure regulator maintain constant output pressure. In the throwing mechanism, the main problem is varying pressure and pressure losses due to leakages. These problems are overcome by pressure regulator By giving electrical inputs, we can maintain constant output pressure so that we will get constant throwing force.

\section{Passing Mechanism}

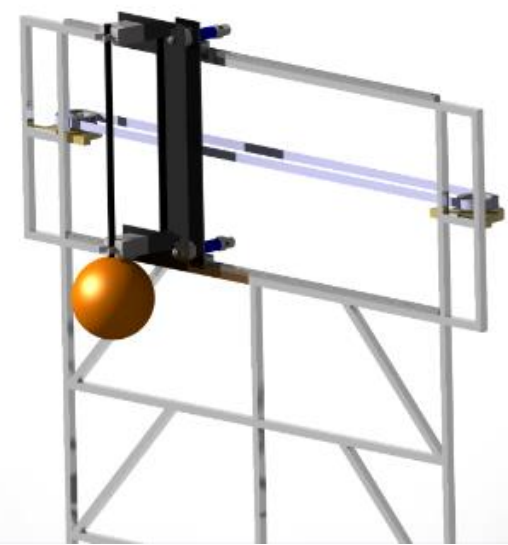

Photograph.4 Shuttlecock passing mechanism

\begin{tabular}{|c|c|c|}
\hline S. No & Part & Specifications \\
\hline 1 & Pneumatic cylinder & $\begin{array}{c}\text { A51/A52 Series } \\
\text { Make- JANATICS }\end{array}$ \\
\hline 2 & Linear guideways & $\begin{array}{c}\text { MGN 12H } \\
\text { Make- HIWIN } \\
\text { Block weight- 54g } \\
\text { Rail weight-0.65 kg/m }\end{array}$ \\
\hline 3 & Pneumatic gripper & $\begin{array}{c}\text { MHC2-16D (angular) } \\
\text { Make- SMC Pneumatics }\end{array}$ \\
\hline 4 & Timing belt model & $\begin{array}{c}\text { LL5MR15T(High Tensile Steel } \\
\text { Belt) }\end{array}$ \\
& & Width- 15mm \\
\hline 5 & Pulleys & $\begin{array}{c}\text { Custom made } \\
\text { Material- Aluminum 7075 } \\
\text { Manufacturing-Milling } \\
\text { Pitch- 5mm }\end{array}$ \\
\hline
\end{tabular}

It consists of two pneumatic cylinder assembly mounted on linear guideways. At the end of each cylinder, two pneumatic grippers are mounted which are used for the purpose of holding and releasing the shuttlecocks while passing to the bot.

Linear drive to the sliding blocks is given by timing belt using stepper motor. The working of motor i.e. steps and directions are manually controlled by controller. Both the grippers are interconnected by means of a carbon fiber plate to avoid misalignment due to rotation of rod of pneumatic cylinder.

\section{Working}

Initially, assembly is at extreme end and both the pistons are in retracted position with opened gripper jaws. After receiving the signal, pistons are first actuated and then grippers to hold the shuttlecock. After this the slider blocks are moved to the passing 
position by the motor. Again, after proper meshing of bots, operator provides signal and again pistons and grippers are actuated to pass shuttlecock to automatic bot. The jaws of manual passing grippers are actuated after automatic bot holds the shuttlecock. Above cycle is repeated after each throw.

Circuit diagram of Pneumatic system

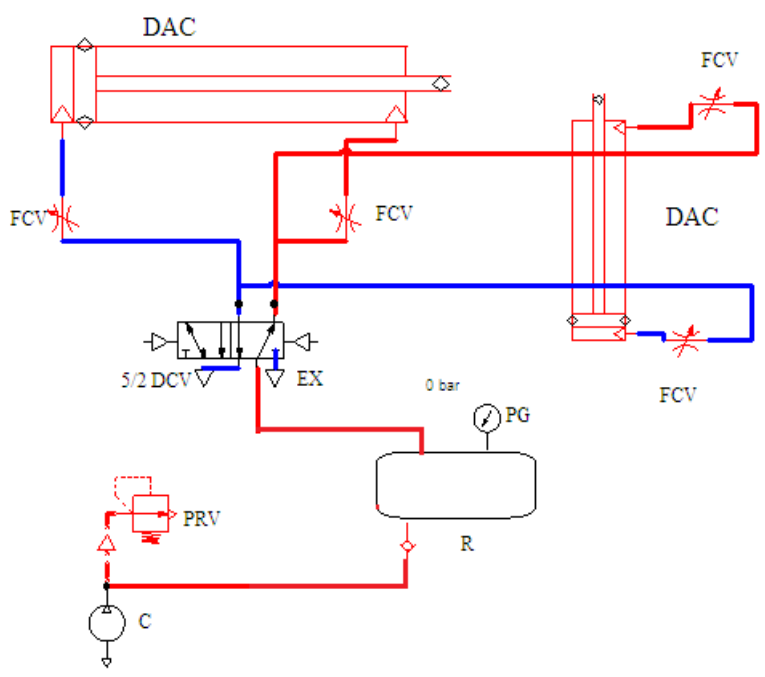

Figure.3 Pneumatic circuit

\section{PCB}

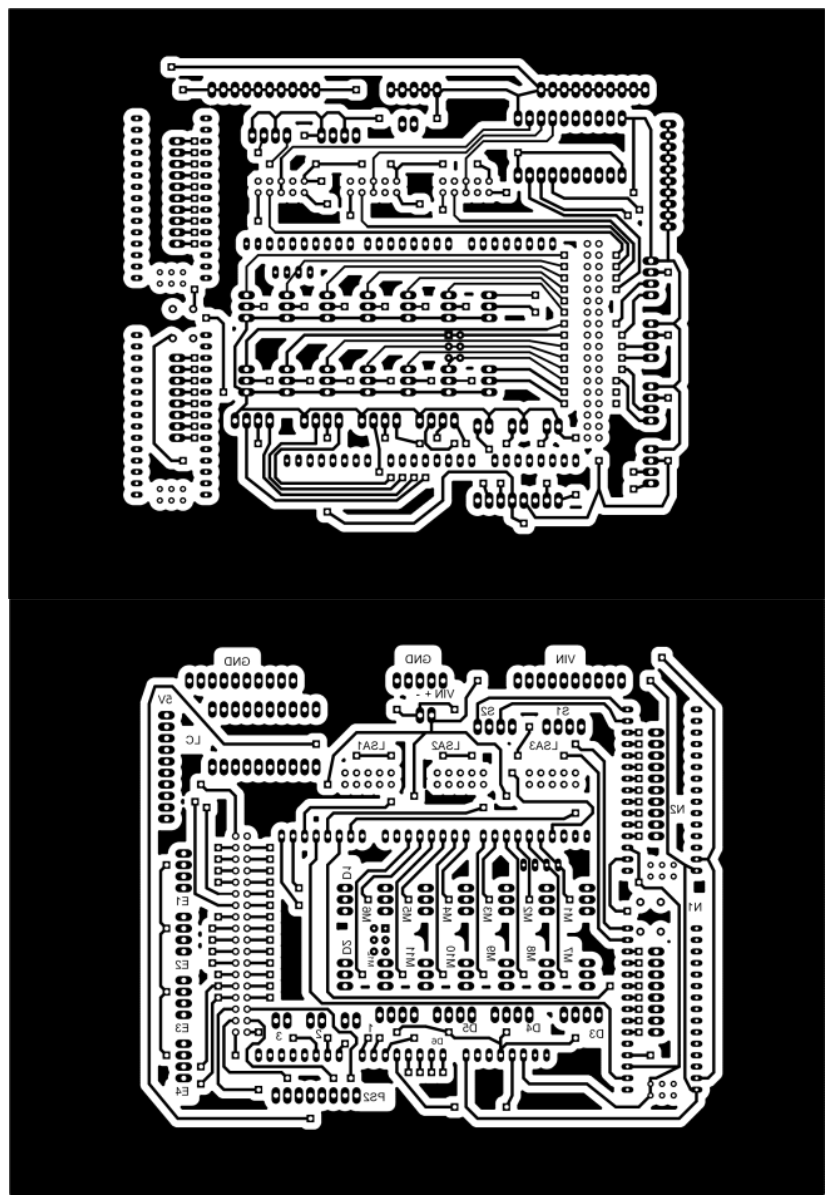

Figure.3 PCB for automatic robot

\section{Assembly}

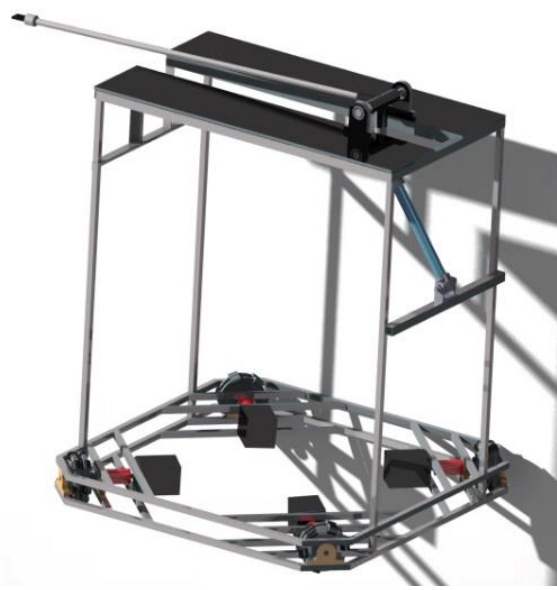

Photograph 5. Automatic robot

\section{Results and Discussions}

Passing Mechanism

The passing mechanism is $100 \%$ efficient. Passing of shuttlecock to the automatic robot was performed accurately unless there was some operating error from manual operator.

\section{Throwing Mechanism}

The values of parameters were as follows while testing Mass of projectile $=0.120 \mathrm{~kg}$

Projectile diameter $=0.120 \mathrm{~m}$

Wind speed $=0.5 \mathrm{~m} / \mathrm{s}$

Mass of $\operatorname{arm}=0.2328 \mathrm{~kg}$

\begin{tabular}{|c|c|c|c|c|}
\hline $\begin{array}{c}\text { Sr } \\
\text { no. }\end{array}$ & Arm length (cm) & $\begin{array}{c}\text { Pressure } \\
(\mathrm{bar})\end{array}$ & $\begin{array}{c}\text { Range } \\
(\mathrm{m})\end{array}$ & $\begin{array}{c}\text { Height } \\
(\mathrm{m})\end{array}$ \\
\hline \multicolumn{5}{|c|}{ Throwing zone 1} \\
\hline 1 & 80 & 5 & 6.6 & 2.6 \\
\hline 2 & 75 & 5 & 6.1 & 2.5 \\
\hline \multicolumn{5}{|c|}{ Throwing zone } \\
\hline 3 & 85 & 5.5 & 9.5 & 3.4 \\
\hline 4 & 85 & 5 & 9.1 & 3.2 \\
\hline
\end{tabular}

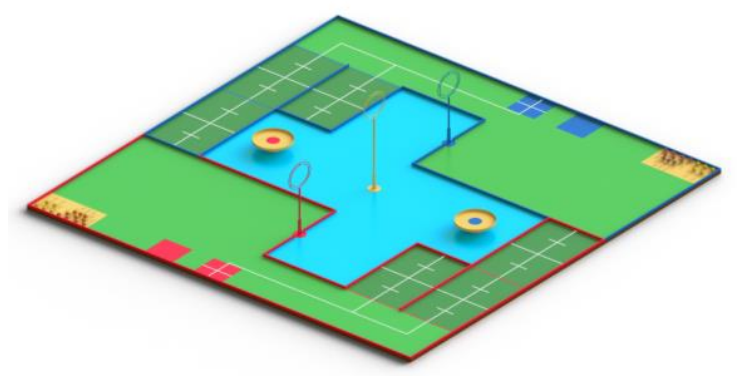

Figure.3 Testing rig

\section{Discussions}

From analyzing the data, following points can be discussed 
1) The rack picking and passing mechanism are $100 \%$ efficient unless there is some error in operating by the manual operator.

2) The throwing mechanism's performance was affected by the inherent errors like pressure fluctuations, uneven shape and weight variations in shuttlecocks.

3) Also, the environmental factors like air flow, ambient air humidity hindered the performance of throwing.

4) Still, the results from software and actual testing were very much synchronous considering the practical limitations.

5) The full-length trials showed that average time for completion of task was about $1 \mathrm{~min} 21 \mathrm{sec}$, provided that first shuttlecock for each throwing zone passes through ring.

6) The mechanical failure of any of the component was not observed during the working of robots.

\section{Conclusion}

- For this project, it was essential that we should follow accordingly to the objectives those were proposed earlier and we are up to it. The methodology was followed at each stage of project with care. We had thoroughly revised the literature survey in order to achieve the required results.

- During the testing on prototypes, it was observed that aerodynamic shape of shuttlecock is of much importance and the pressure level in the reservoir should be monitored for getting equal range. So, to overcome this, we have selected the pressure regulator.
- Also, the alignment of manual robot with automatic robot is the utmost important factor. Accordingly, we modified the design to be sure each time of proper alignment. Finally, all the parameters for ideal throwing of the shuttlecock were finalised.

\section{Future Scope}

In this project, the robots designed and manufactured were task-specific robots. That is, they are built to perform that specific task only. But with the slight modifications in the mechanisms developed and the logic proposed for functioning of robots, they can be used in various applications. In future, they could be useful in following ways:

- Can be used in warehouses, for stacking purposes or for lifting purposes.

- For sports purposes, like throwing of balls or objects.

- The flow of processes can be altered for the home automation purposes.

- $\quad$ Passing and navigation control can be utilised in the material handling equipments.

\section{References}

G.W.Parker, 1977, Projectile motion with air resistance quadratic in the speed, Department of Physics, North Carolina State University, Raleigh, North Carolina 27607

Donald B. Siano, 2001, Trebuchet Mechanics

Raul Rojas, 2005, Omnidirectional Control, Freie Universität Berlin

Ranjit Barua, Sajal Mandaand Dr. SamiranMandal, 2001, Motion Analysis of a Mobile Robot with Omni-Directional Wheels, Mechanical Engineering Department, NITTTRKolkata,

Salt Lake, Sector-III, Kolkata-700106, India

S. Graham Kelly, The book on Mechanical Vibrations- Theory and Applications Cengage Learning Publications. 